\title{
Consistency of Frictional Temperature and Wear on Indicating the Critical Thickness for Disc Brake Replacement by Finite Element Model
}

\author{
Eric Amoah Asante ${ }^{1, ~ *, ~ M i c h a e l ~ A d u s e i-B o n s u ~}{ }^{1}$, Randy Amuaku², Edward Ampaw ${ }^{2}$ \\ ${ }^{1}$ Department of Agricultural and Biosystems Engineering, College of Engineering, Kwame Nkrumah University of Science and Technology, \\ Kumasi, Ghana \\ ${ }^{2}$ Department of Mechanical Engineering, Faculty of Engineering, Koforidua Technical University, Koforidua, Ghana
}

\section{Email address:}

ericasante@knust.edu.gh (E. A. Asante)

${ }^{*}$ Corresponding author

\section{To cite this article:}

Eric Amoah Asante, Michael Adusei-Bonsu, Randy Amuaku, Edward Ampaw. Consistency of Frictional Temperature and Wear on Indicating the Critical Thickness for Disc Brake Replacement by Finite Element Model. Advances in Applied Sciences. Vol. 6, No. 2, 2021 , pp. 34-42. doi: $10.11648 /$ j.aas.20210602.15

Received: May 14, 2021; Accepted: June 4, 2021; Published: June 21, 2021

\begin{abstract}
Reduced thickness reduces the heat dissipation capacity of the brake disc and its mechanical strength, triggering a series of critical faults and failures. To determine the critical thickness for disc replacement, a transient analysis for contact problem of disc brakes with frictional heat was performed using finite element method. To analyze the effect of disc thickness on the frictional heat generation, different brake disc models were developed with disc thicknesses of $5.0 \mathrm{~mm}, 5.5 \mathrm{~mm}, 6.0 \mathrm{~mm}, 6.5$ $\mathrm{mm}, 7.0 \mathrm{~mm}, 7.5 \mathrm{~mm}$ and $8.0 \mathrm{~mm}$. Subsequently, the developed disc models were evaluated under $2210 \mathrm{~N}, 2875 \mathrm{~N}$ and $3538 \mathrm{~N}$ braking forces and $884 \mathrm{rpm}, 1149 \mathrm{rpm}$ and $1415 \mathrm{rpm}$ rotational speed of the disc. The numerical simulation for the thermoelastic behavior of disk brake was obtained in the repeated brake condition by Finite Element Analysis package of SolidWorks. The results showed that increasing the braking force from $2210 \mathrm{~N}$ to $2875 \mathrm{~N}, 2875 \mathrm{~N}$ to $3538 \mathrm{~N}$ and $2210 \mathrm{~N}$ to $3538 \mathrm{~N}$ resulted in $28.45 \%, 33.62 \%$ and $52.5 \%$ deformations respectively. Subsequently, increasing the rotational speed of the disc from $884 \mathrm{rpm}$ to $1149 \mathrm{rpm}, 1149 \mathrm{rpm}$ to $1415 \mathrm{rpm}$ and $884 \mathrm{rpm}$ to $1415 \mathrm{rpm}$ resulted in $69.57 \%, 17.23 \%$ and $74.8 \%$ deformations respectively. Though, the differences in successive forces is the same, the percentage deformation was not the same but rather a decline in the increase. In the case of the ultimate stress, the application of $884 \mathrm{rpm}, 1149 \mathrm{rpm}$ and $1415 \mathrm{rpm}$ speeds at the same braking force of $2210 \mathrm{~N}$ yielded $1.327 \times 1011 \mathrm{~N} / \mathrm{m}^{2}, 2.069 \times 1011 \mathrm{~N} / \mathrm{m}^{2}$ and $2.072 \times 1011 \mathrm{~N} / \mathrm{m}^{2}$ ultimate stresses respectively. Increasing the rotational speed of the brake disc from $884 \mathrm{rpm}$ to $1149 \mathrm{rpm}$ and $1149 \mathrm{rpm}$ to $1415 \mathrm{rpm}$ resulted in $35.86 \%$ and $0.14 \%$ ultimate stress respectively. The overall results have shown that, under the same condition of treatment; effect of braking force $>$ effect disc rotational speed $>$ effect of disc thickness. There was a sharp drop in temperature at all the radii points where readings were taken and this could be due to initial heat transfer from the disc to the pad just at contact. The minimum thickness for optimal heat and wear reduction $6.7 \mathrm{~mm}$. The present study can provide a useful design tool and improve the brake performance of disk brake system.
\end{abstract}

Keywords: Disc Brake, Transient Heat, Wear, Solid Works Simulation, Critical Thickness

\section{Introduction}

Brakes are widely used in mechanical equipment such as automobiles, aircraft, cranes, turbines and many moving equipment to ensure operational safety and stability. $[1,2]$. Because of the advantages of stable braking performance and large torque capacity, the disc brake has become one of the most progressive brake devices. Wear takes place on the discs of disc brake systems and the brake pads during deceleration $[3,4]$. Parts of the wear particles deposit on the ground and some suspend in the air as particle pollutions $[5,6]$. The disc brake is used to stop the high-speed equipment with heavy load under emergency braking condition. Large amount of heat is generated by the friction effect of the brake disc and 
pad throughout the whole braking process. The effect is heat dissipation and thermal damage to the brake pad. [7, 8]. A small part of the heat is stored in the friction material as internal energy.

Distortion and wear of material could occur on the brake pad because of uneven distribution of the large quantity of heat $[9,10]$. Due to the friction, the heat generated causes localized high temperature at the contact surface and uneven thermal deformation of the brake pad. The situation leads to an uneven dispersal of the stress between the brake disc and the contact area of the pad. Therefore, the effect of braking performance degradation on the variation of the wear condition of the brake disc and pad has become the focus of many research work.

Thermal enlargement and geometrical defects are the key causes of uneven distribution of friction heat. Besides, thermoelastic distortion affects the contact stress distribution and leads to thermoelastic instability. In the situation where the contact stress is concentrated in one or more small regions on the brake disc surface, these regions develop very high temperatures at low frequencies. Disc thickness variation will further promote the localized contact. Nonuniform contact can also be generated by disc lateral runout. As a result, many research works have been carried out on friction wear rate, thermal heat and braking system performance due to variation in the disc and brake pad contact pressure and brake pad material composition. For instance [11], investigated the effects of variations in disc brake contact conditions on the heating patterns and judder characteristics using modified baseline friction material based on the theory of thermoelastic instability and dynamometer testing. In another study, [12], developed a numerical technique to characterize the contact temperature problem of composite materials, and reported that the contact temperature distribution between real composite-steel surfaces could be evaluated in sliding contact. Subsequently, some researchers examined finite element models for studying the friction heat of the disc brake to obtain the temperature distribution and the thermal and residual stresses [13-16]. The generation of friction heat is affected by the braking conditions, determined by the braking parameters. The braking parameters have a major impact on the wear [17]. Operation of a brake below the maximum permissible temperature determines safety, effectiveness and low wear of the sliding components through the interactions of the parameters in the process [18]. These parameters are the initial velocity, contact pressure, coefficient of friction and many more. The last parameter which is attributed to the materials used, is the ratio between the force acting on the body in the normal direction and the resulting frictional force, which should be maintained constant $[18,19]$. Despite the numerous achievements in the area of disc and brake pad wear research, there is limited data on the effect of disc thickness on frictional heat. Furthermore, the best combination of disc thickness, wheel velocity and braking pressure for effective braking is unknown. Also, developing a 3D finite element analysis model to investigate the wear rate for different disc thickness will provide comprehensive data for brake disc and pad wear researchers and the local automobile industry. Therefore, this study seeks to: (1) Develop ventilated 3D disc brake models with similar geometrical parameters but different thickness which could be used to assess the heat and wear rate under single stop braking. (2) Investigate the effect of wheel speed and disc thickness on temperatures and wear rate for the developed ventilated disc models by Finite Element Analysis. (3) Determine the transient temperature developed at different radii under the same braking durations for the different disc models. (4) Assess the influence of wheel velocity on the stress, factor of safety and disc and pad wear.

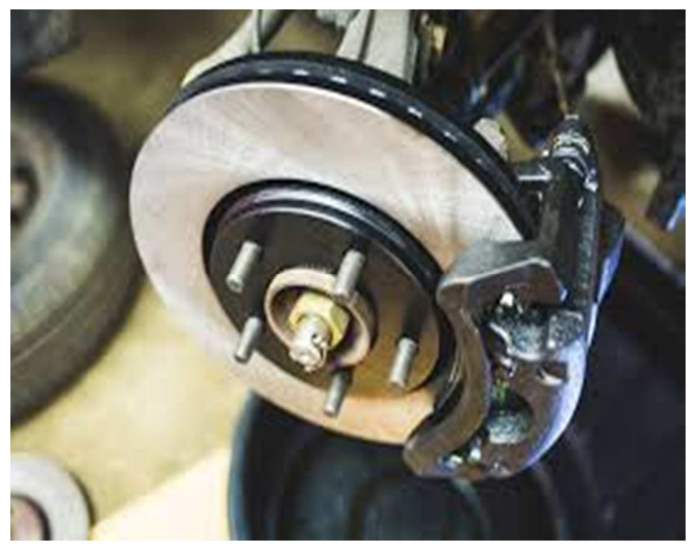

(a) Pictorial view

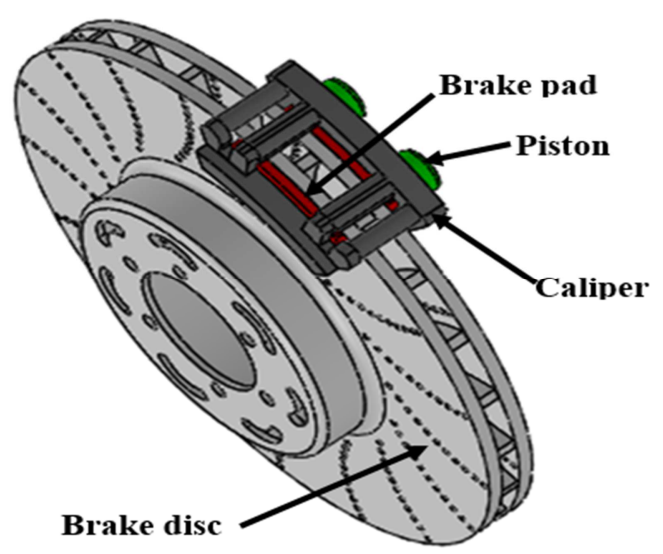

(b) 3D Developed model

Figure 1. Nomenclature of the brake disc.

\section{Materials and Methods}

\subsection{Description of the Study Area and Sampling}

The design and development of the ventilated disc models were carried out using SolidWorks 2020 version software. Subsequently, the disc brake system and the simulations were conducted.

Pressure from the cylinder causes the pads to exert friction torque on the shaft. This friction torque resists the shaft rotation. The focus of this study was on ventilated brake disc because it is modern with complex shapes and could be used at both the rear and front axles of vehicles. They constitute two broken crowns which are separated by fins (Figure 1b). 


\subsection{Conception of Finite Element Model for the Brake Pad Wear}

The study of friction and wear characteristics of the disc and brake pad during the braking process of high-power disc brake require that one establish a friction heat generation model. This will enable the researcher to intensely investigate the wear process. In this case the following assumptions were made.

The contact interface of the friction pair is an ideal plane.

The friction condition accords with Coulomb's law and the friction factor is constant during the disc braking.

The friction heat generated on the inner and outer sides of the brake pad is equal, so only one side of the brake disc is considered.

The instantaneous temperature of the corresponding point on the contact area of the brake disc and the brake pad is equal.

Assume that the pressure is evenly distributed on the brake pad.

The material of the brake disc and the brake pad is an isotropic material. Due to the short emergency braking time, the thermal property parameters of the material do not change with temperature.

The cross section of the brake disc is shown in Figure 2. $R_{\text {out }}, R_{\text {mid }}$, and $R_{\text {in }}$ are the upper, middle the lower radii on the wear surface where the transient temperature is measured after the simulation.

$D_{1}$ and $D_{2}$ stands for the thickness of the brake pad and the brake disc respectively; $\varphi$ is the wrap angle of the brake pad. The details of the parameters are shown in Table 1.

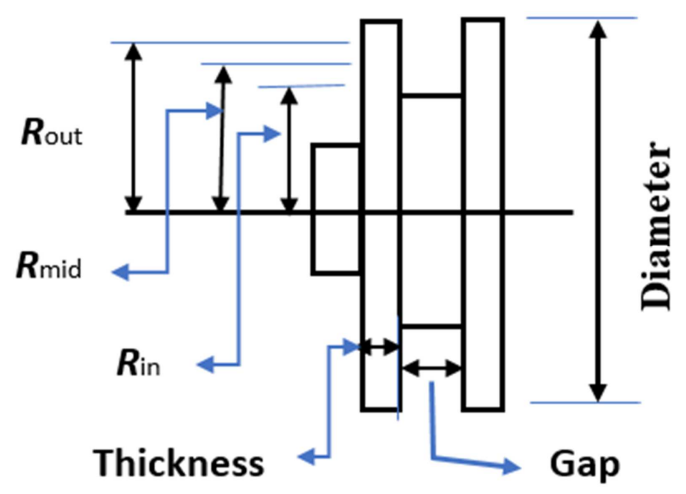

Figure 2. Proposed sectional view of the disc model.

Table 1. Geometrical parameters used for the ventilated disc.

\begin{tabular}{ll}
\hline Parameters & Values \\
\hline Outside diameter of the disc, $\mathrm{mm}$ & 250 \\
Inside diameter of the disc, $\mathrm{mm}$ & 130 \\
Effective disc radius, $R_{\text {disc }}, \mathrm{mm}$ & 95 \\
Swept area of the disc surface, $A_{d}, \mathrm{~mm}^{2}$ & $9,311.2$ \\
Data collection location from disc center, $R(\mathrm{~mm})$ & $75,95,115$ \\
\hline
\end{tabular}

\subsection{Disc Parameter Consideration for the Simulation}

The parameters used for each simulation models are shown in table 2 . The ventilated gap was maintained at $10 \mathrm{~mm}$ for all the six (6) models. However, the disc plate thickness was varied at a reduction rate of $0.25 \mathrm{~mm}$ on each side of the disc brake making the total thickness to reduce by $0.5 \mathrm{~mm}$. Therefore, the thickness reduces from $8 \mathrm{~mm}$ to $7.5,7.0,6.5$, 6.0 and $5.5 \mathrm{~mm}$ (Table 2)

Table 2. Disc thickness variations used for the simulation

\begin{tabular}{|c|c|c|c|}
\hline Ventilation gap & Disc height & Disc thickness & Disc wear \\
\hline (G) $\mathrm{mm}$ & (H) $\mathrm{mm}$ & (T) $\mathrm{mm}$ & $(\mathrm{W}) \mathrm{mm}$ \\
\hline 10 & 26 & 8.0 & 0 \\
\hline 10 & 24 & 7.0 & 1.0 \\
\hline 10 & 23 & 6.5 & 1.5 \\
\hline 10 & 22 & 6.0 & 2.0 \\
\hline
\end{tabular}

The properties used for the simulation analysis of thermal (transient type), solid mesh type, curvature-based mesh, and total time of 3 seconds at 0.1 second increment is presented in Table 3.

Table 3. Analysis properties

\begin{tabular}{ll}
\hline Study name & Study properties \\
\hline Analysis type & Thermal (Transient) \\
Mesh type & Solid Mesh \\
Mesher used & Curvature-based mesh \\
Total time & 3 Seconds \\
Time increment & 0.1 Seconds \\
\hline
\end{tabular}

\subsection{FE model and Simulation}

In this study, three-dimensional CAD and FE model which consists of a ventilated disc as illustrated in Figure $1 \mathrm{~b}$ was performed. The materials of the disc and the pads are homogeneous and their properties are invariable. A commercial FE software, namely SolidWorks 2020 was fully utilized to simulate the structural deformation and contact pressure distributions of the disc brake during single braking application. Boundary conditions are imposed on the models (disc-pad) for applied pressure on both sides of the pad. The disc was rigidly constrained at the bolt holes in all directions except in its rotational direction. Meanwhile, the pad is fixed at the support in all degrees of freedom except in the normal direction to allow the pads move up and down and in contact with the disc surface. Using the disc data as given in Table 1, the braking force on the disc, rotational speed and brake pressure on the pad can be determined.

\subsection{Design Calculations}

The rotational speed of the disc was calculated as follows: 


$$
\omega=\frac{v_{o}}{R_{\text {tire }}}
$$

Where, $\omega$ is the angular velocity of the disc, $v_{0}$ is the linear velocity of the vehicle and $R_{\text {tire }}$ is the outer radius of the tire.

The external pressure between the disc and the pads was calculated by the force applied to the disc; for a flat track, the hydraulic pressure is, as referred to $[13,20,21]$.

$$
p=\frac{F_{\text {disc }}}{A_{p} \mu}(M P a)
$$

Where, $F_{\text {disc }}$ is the surface area of the brake pad in contact with the disc and $\mu$ is the coefficient of friction between the disc and the pad.

The contact area of the brake pad $A_{p}$ was calculated using the equation:

$$
A_{p}=\frac{\theta}{360^{0}} \pi\left(R^{2}-r^{2}\right)
$$

Where, $\theta$ is the angle subtended by the sector formed from the contact surface, $R$, is the outer radius of the pad and $r$ is the inner radius of the pad.

Given that, $R=0.15 \mathrm{~m}, r=0.095 \mathrm{~mm}, \theta=60^{\circ}$ and $\pi=$ 3.142 , then the contact area of the pad is:

$$
A_{p}=\left(\frac{60}{360^{0}}\right) * 3.142 *\left(0.15^{2}-0.095^{2}\right)=7.056 \times 10^{-3} \mathrm{~m}^{2}
$$

\subsection{Finite Element Analysis}

\subsubsection{Thermal Analysis}

A finite element simulation of frictional heating of the pad and the disc during a single braking process from the initial velocity of a rotating brake disc to standstill was carried out using SolidWorks. The considered transient nonlinear case of numerical analysis resulted the computational time may lengthen significantly and resulted into a linear problem. Therefore, it was important to find the minimum number of elements of the FE model of a brake satisfying the accuracy and efficiency requirements. Hexahedral meshes in the total number of elements of were built and the transient temperatures on the friction surface were determined. Due to high temperature gradient, the main feature of the FE model of the disc brake was the application of non-uniform distribution of dimension of an element in the axial direction. The finer mesh with reasonable limit was used in this study. However, the time step $\Delta \mathrm{t}$ was selected automatically by the solver, the time step of the results was matched. In this study, the time step was $\Delta t=0.1 \mathrm{~s}$.

\subsubsection{Processes Involved in the Thermal Analysis}

The processes involved in the thermal analysis are:

Simulation was selected and the name for the particular task given as thermal ventilated.
Properties for the simulation was defined as transient because it involved temperature distribution over a given time period. The total braking time was set at $3 \mathrm{~s}$ at an incremental time of $0.1 \mathrm{~s}$.

Alloy steel (cast alloy steel) was selected as the disc material and applied to all the parts.

The boundary conditions under thermal loading was then applied to all the exposed surfaces. A conversion coefficient of $90 \mathrm{~W} / \mathrm{m}^{2} . \mathrm{K}$ and a bulk ambient temperature of $293 \mathrm{~K}$ was applied. The time curve was set up for the conversion coefficient. This was done by selecting the time curve icon and clicking edit. There are two columns in this case. The first column $(\mathrm{x})$ represented the time period in the simulation and the second column (y) represented the conversion coefficient multiply by. There were two rows for each column and in the first row, ' $x$ ' $=0$ and ' $y$ ' $=1$; in the second row, ' $x$ ' $=3$ and ' $y$ ' $=1$ and then accepted by clicking okay. Note that in this study the conversion coefficient was constant throughout the study.

The thermal load was then added for the heat power. This is the heat that was transferred through the brake pad into the brake loader. This value was calculated using the equations as follows:

$$
\text { Kinetic energy, } K E=\frac{1}{2} m v^{2}
$$

Where, $\mathrm{m}$ is the mass of the car and $\mathrm{v}$ is the speed of the car.

$$
\text { Heat power, } H P=\frac{K E}{\Delta t}
$$

Where, $\Delta t$ is the time it takes the car to stop.

However, only one part of the brake is being analyzed. Therefore, the heat power for the one brake system is given by:

Heat power for one brake $H P_{\text {one-brake }}=\frac{0.6 \text { heat, } \text { power }_{\text {total }}}{2}$

In this case the heat power was set at 6660 Watts and the time curve was added by setting the time curve as: first row, ' $x$ ' $=0$ and ' $y$ ' $=1$; second row, ' $x$ ' $=3$ and ' $y$ ' $=1$ and then accepted by clicking okay.

The initial temperature was set to $25^{\circ} \mathrm{C}$. This was before the simulation can only be ran after defining the initial temperature. This was done by clicking on the thermal load under the study and selecting temperature.

The final stage was to create the mesh for the study and this was done by defining the mesh parameters of $3 \mathrm{~mm} \times 0.15 \mathrm{~mm}$ under the curvature base mesh.

Then the running of the simulation was carried out.

Post processing was done by selecting the probe tool to determine the temperature of one area over the entire time frame. This was done by going to the probe tool and a point was selected. Subsequently, the temperature icon was selected and the temperature distribution over the entire time was plotted. 
Table 4. Properties of the materials used for the brake disc and pad.

\begin{tabular}{lll}
\hline \multirow{2}{*}{ Parameters } & Values & \\
\cline { 2 - 3 } & Disc & Pad \\
\hline Thermal conductivity, $\mathrm{k}\left(\mathrm{W} / \mathrm{m}^{\circ} \mathrm{C}\right)$ & 57 & 5 \\
Volumetric mass density, $\rho\left(\mathrm{kg} / \mathrm{m}^{3}\right)$ & 7250 & 1400 \\
Specific heat capacity, $\mathrm{c}\left(\mathrm{J} / \mathrm{kg} .{ }^{\circ} \mathrm{C}\right)$ & 460 & 1000 \\
Poisons ratio, $\nu$ & 0.28 & 0.25 \\
Friction coefficient, $\mathcal{M}$ & 0.2 & 0.2 \\
Youngs modulus, $\mathrm{E}(\mathrm{GPa})$ & 138 & 1 \\
\hline
\end{tabular}

\section{Results and Discussion}

\subsection{Effect of Different Forces and the Same Speed}

The images of the output from the simulation for the deformation, ultimate stress and factor of safety under $2210 \mathrm{~N}$, $2875 \mathrm{~N}$ and $3538 \mathrm{~N}$ at disc rotational speed of $884 \mathrm{rpm}$ are shown in figure 3 . It was difficult to qualitatively evaluate the result and therefore, quantitative analysis is the best way. Application of $2210 \mathrm{~N}, 2875 \mathrm{~N}$ and $3538 \mathrm{~N}$ forces at the same disc rotational speed of $884 \mathrm{rpm}$ yielded $0.101 \mathrm{~mm}, 0.141 \mathrm{~mm}$ and $0.212 \mathrm{~mm}$ minimum deformations respectively with 0.151 $\mathrm{mm}$ as the average. Increasing the braking force from $2210 \mathrm{~N}$ to $2875 \mathrm{~N}$ and $2875 \mathrm{~N}$ to $3538 \mathrm{~N}$ and $2210 \mathrm{~N}$ to $3538 \mathrm{~N}$ resulted in $28.45 \%, 33.62 \%$ and $52.5 \%$ deformations respectively. Though, the difference in successive forces is the same, the percentage successive wear was not the same but rather increased to about $5 \%$ higher which could be due to excessive and cumulated heating by the increase in the force [22].

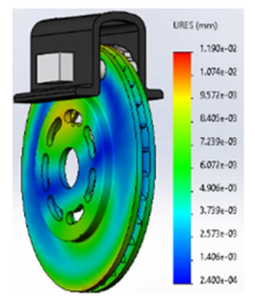

(a) $884 \mathrm{rpm} ; 2210 \mathrm{~N}$

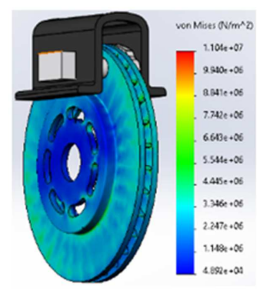

(d) $884 \mathrm{rpm} ; 2210 \mathrm{~N}$

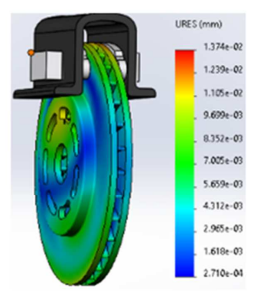

(b) $884 \mathrm{rpm} ; 2875 \mathrm{~N}$

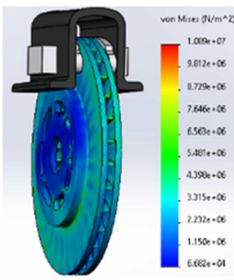

(e) $884 \mathrm{rpm} ; 2875 \mathrm{~N}$

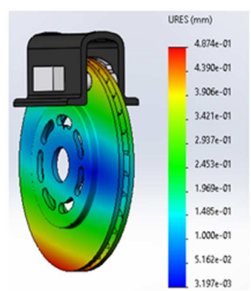

(c) $884 \mathrm{rpm} ; 3538 \mathrm{~N}$

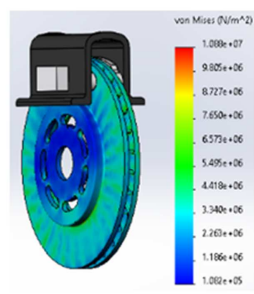

(f) $884 \mathrm{rpm} ; 3538 \mathrm{~N}$
Figure 3. Effect of different forces at the same speed on deformation and stress.

In the case of the ultimate stress developed, the application of $2210 \mathrm{~N}, 2875 \mathrm{~N}$ and $3538 \mathrm{~N}$ forces at the same disc rotational speed of $884 \mathrm{rpm}$ yielded $2.34 * 10^{11} \mathrm{~N} / \mathrm{m}^{2}, 3.19 * 10^{11} \mathrm{~N} / \mathrm{m}^{2}$ and $3.82 * 10^{11} \mathrm{~N} / \mathrm{m}^{2}$ ultimate stresses respectively. Increasing the braking force from $2210 \mathrm{~N}$ to $2875 \mathrm{~N}$ and $2875 \mathrm{~N}$ to $3538 \mathrm{~N}$ resulted in $26.56 \%$ and $16.43 \%$ in the ultimate stress respectively. Though, the difference in successive force is the same, ultimate stress increased with about $10 \%$ difference which is significant and this could be due to cumulated yielding of the material to increase in the force. The factor of safety showed that increasing the braking force from $2210 \mathrm{~N}$ to 2875 $\mathrm{N}$ and $2875 \mathrm{~N}$ to $3538 \mathrm{~N}$ reduced the factor of safety by $7.49 \%$ and $36.12 \%$ respectively (Figure 4 ). Though, the difference in successive force is the same, factor of safety decreased significantly and this could be due to the higher braking risk that the brake disc was subjected to by the higher force [23].

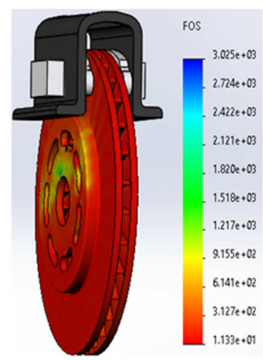

(a) $884 \mathrm{rpm} ; 2210 \mathrm{~N}$

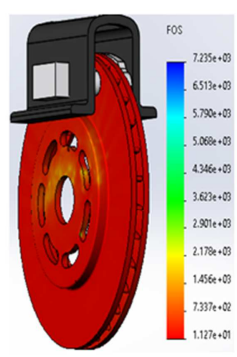

(b) $884 \mathrm{rpm} ; 2875 \mathrm{~N}$

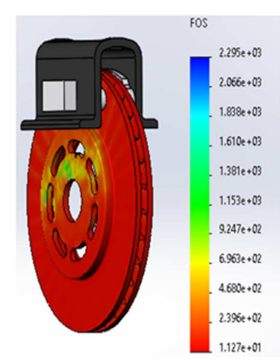

(c) $884 \mathrm{rpm} ; 3538 \mathrm{~N}$
Figure 4. Effect of different forces at the same speed on the factor of safety.

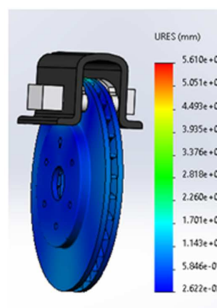

(a) $2210 \mathrm{~N} ; 884 \mathrm{rpm}$

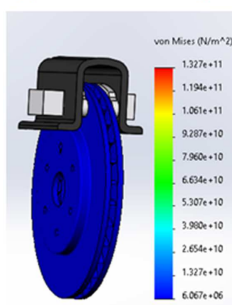

(d) $2210 \mathrm{~N} ; 884 \mathrm{rpm}$

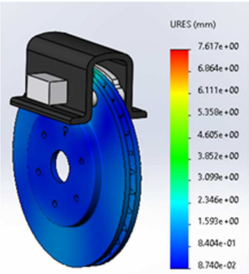

(b) $2210 \mathrm{~N} ; 1149 \mathrm{rpm}$

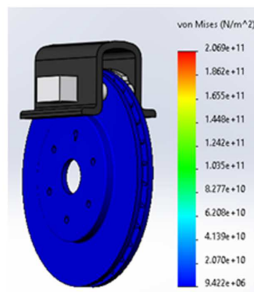

(e) $2210 \mathrm{~N} ; 1149 \mathrm{rpm}$

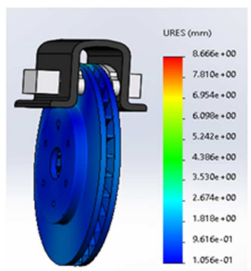

(c) $2210 \mathrm{~N} ; 1415 \mathrm{rpm}$

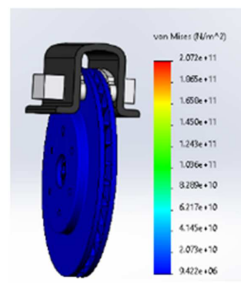

(f) $2210 \mathrm{~N} ; 1415 \mathrm{rpm}$
Figure 5. Effect of different speeds at the same force on deformation, stress and factor of safety.

\subsection{Effect of Different Speeds and The same Braking Force}

The images of the output from the simulation for the deformation, ultimate stress and factor of safety under the maximum force of $2210 \mathrm{~N}$ at disc rotational speeds of $884 \mathrm{rpm}$, $1149 \mathrm{rpm}$ and $1415 \mathrm{rpm}$ are shown in figure 5. Quantitative evaluation of the result showed that disc rotational speeds of $884 \mathrm{rpm}, 1149 \mathrm{rpm}$ and $1415 \mathrm{rpm}$ under $2210 \mathrm{~N}$ force yielded $0.0266 \mathrm{~mm}, 0.0874 \mathrm{~mm}$ and $0.1056 \mathrm{~mm}$ minimum deformations respectively. Increasing the rotational speed of the disc from $884 \mathrm{rpm}$ to $1149 \mathrm{rpm}, 1149 \mathrm{rpm}$ to $1415 \mathrm{rpm}$ and $884 \mathrm{rpm}$ to $1415 \mathrm{rpm}$ resulted in $69.57 \%, 17.23 \%$ and $74.8 \%$ deformations respectively. Though, the difference in successive forces is the same, the percentage deformation was 
not the same but rather there was a decline in the increase. In the case of the ultimate stress, the application of $884 \mathrm{rpm}$, $1149 \mathrm{rpm}$ and $1415 \mathrm{rpm}$ speeds at the same braking force of $2210 \mathrm{~N}$ yielded $1.327 * 10^{11} \mathrm{~N} / \mathrm{m}^{2}, 2.069 * 10^{11} \mathrm{~N} / \mathrm{m}^{2}$ and $2.072 * 10^{11} \mathrm{~N} / \mathrm{m}^{2}$ ultimate stresses respectively. Increasing the rotational speed of the brake disc from $884 \mathrm{rpm}$ to 1149 $\mathrm{rpm}$ and $1149 \mathrm{rpm}$ to $1415 \mathrm{rpm}$ resulted in $35.86 \%$ and $0.14 \%$ ultimate stress respectively.

This means that increasing the speed from $884 \mathrm{rpm}$ to 1415 rpm increased the ultimate stress by $35.96 \%$. Therefore, the effect of increasing the force on the ultimate stress is more pronounced than increasing the rotational speed of the brake disc [24]. Quantitative evaluation of safety factor showed that increasing the rotational speed of the disc brake reduces the factor of safety (Figure 5). Increasing the rotational speed of the disc from $884 \mathrm{rpm}$ to $1149 \mathrm{rpm}$ and $1149 \mathrm{rpm}$ to $1415 \mathrm{rpm}$ reduced the factor of safety by $23.2 \%$ and $20.7 \%$ respectively. Though, there were difference in the successive reduction of the factor of safety, it was not significant due to the little influence on the increase in speed. Though, the difference in successive force is the same, factor of safety decreased significantly and this could be due to the higher braking risk the brake disc was subjected to by the higher force.

\subsection{Effect of Different Disc Thickness on Disc Performance}

Quantitative evaluation of the result showed that reducing the disc thickness from $8.0 \mathrm{~mm}$ to $7.5 \mathrm{~mm}$ and $7.5 \mathrm{~mm}$ to $7.0 \mathrm{~mm}$ resulted in $13.18 \%$ increment and $0.21 \%$ reduction respectively. Subsequently, reducing the disc thickness from $7.0 \mathrm{~mm}$ to $6.5 \mathrm{~mm}$ yielded $13 \%$. In another development, $14.6 \%$ and $14.2 \%$ successive reductions were obtained for reducing the thickness of the brake disc from $6.5 \mathrm{~mm}$ to 6.0 $\mathrm{mm}$ and $6.0 \mathrm{~mm}$ to $5.5 \mathrm{~mm}$ respectively. This indicated that the change in the disc thickness was almost directly proportional to reduction in the factor of safety [25].

Overall, it can be concluded that the effect of braking force, rotational speed of the disc and the disc thickness under the same condition of treatment can be ranked as; braking force $>$ effect of disc rotational speed $>$ effect of disc thickness.

\subsection{Numerical Analysis}

\subsubsection{Thermal Stress}

The FE considered for thermal analysis of the disc brake system is shown in Figure 6. Due to high temperature gradient, the main feature of the FE model of the disc brake was the application of nonuniform distribution of elements in the axial direction. The finer mesh with reasonable limit was used in this study.

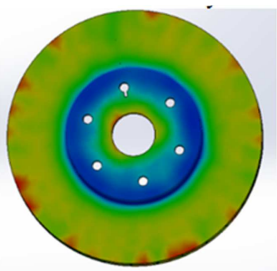

(a) front side of the disc

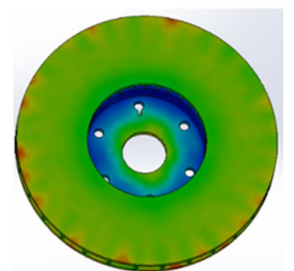

(b) Back side of the disc
Figure 6. Simulated image of the disc showing the heat stress.

\subsubsection{Temperature Distribution for Different Disc Radii}

Figure 7 shows the variation of the temperature against time during the total time simulation of braking for a ventilated disc at $75 \mathrm{~mm}, 100 \mathrm{~mm}$ and $127 \mathrm{~mm}$ radii from the centre of the disc. The trend showed that the temperature dropped sharply to $0.2 \mathrm{~s}$ for the $75 \mathrm{~mm}$ radius before rising to the maximum at the final time.

In another development, the temperature changes for the $100 \mathrm{~mm}$ and $127 \mathrm{~mm}$ radii dropped sharply to a minimum at $0.3 \mathrm{~s}$ before increasing to the individual maximums at the final braking time respectively (Figure $7 \mathrm{a}$ ). There was a similar trend for all the heat generated at all the radii for the $3 \mathrm{~mm}$ wear (Figure $7 b$ ). The sharp drop in temperature at all the radii points where readings were taken could be due to initial heat transfer from the disc just at contact. The initial temperature of the pad before contact is always lower than that of the disc because it is separated from the disc, does not rotate and highly ventilated. Therefore, a small portion of the initial heat generated due to contact friction is absorbed by the brake pad material and the amount of heat that is absorbed depends to a large extend on the thermal conductivity of the pad material [26]. The temperature distribution increases from the center of the disc to the circumference and the trend is the same for all the disc thickness. The highest temperature was obtained at the $127 \mathrm{~mm}$ radius with the lowest being at the $75 \mathrm{~mm}$ radius for all the braking durations (Figure 7). The lower temperature obtained at the $75 \mathrm{~mm}$ radius was because a large portion of the whole disc material is concentrated around this radius and takes part in the heat absorption process. The strong rise in temperature is due to the short duration of the braking phase and to the speed of the physical phenomenon [27].

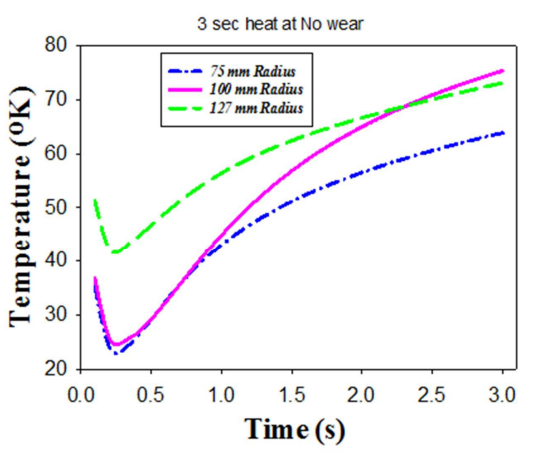

(a) No wear

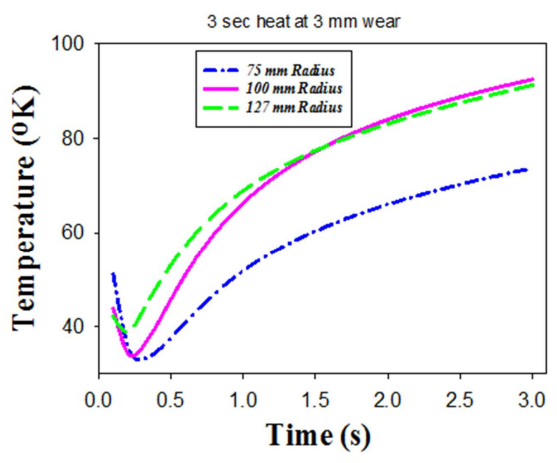

(b) $3 \mathrm{~mm}$ wear

Figure 7. Heat at different radii for (a) No wear and (b) $3 m m$ wear. 
Figure $8 \mathrm{~b}$ presents the mean temperature for the starting, minimum and the maximum averaged over all radii. The trend indicated that the starting temperature is higher than the minimum but lower than the maximum at all the levels of the disc wear. There was a gentle rise of the starting temperature from 0 to $1.0 \mathrm{~mm}$ wear then dropped gently to about $2.1 \mathrm{~mm}$ wear before rising slowly again. Similarly, there was a gentle rise of the minimum temperature from 0 to $1.5 \mathrm{~mm}$ wear then dropped gently to about $2.25 \mathrm{~mm}$ wear before rising slowly again. However, the trend for the maximum temperature showed a gradual rise throughout except between $1.25 \mathrm{~mm}$ and $2.0 \mathrm{~mm}$ wear where it almost plateaus. The average temperature of the starting, minimum and the maximum was lower than only the maximum.

\subsubsection{Effect of Disc Thickness on Temperature}

The wear of brake disc results in reduction of the thickness. In order to determine the effect of thickness reduction on the heat generated and disc deformation, different disc thicknesses were used for the simulation. The results showed that the more the wear level the less the thickness of the disc. Subsequently, the higher the wear the higher the heat developed (Figure 8a).

Figure $8 \mathrm{~b}$ presents the mean temperature for the starting, minimum and the maximum averaged over all radii. The trend indicated that the starting temperature is higher than the minimum but lower than the maximum at all the levels of the disc wear. There was a gentle rise of the starting temperature from 0 to $1.0 \mathrm{~mm}$ wear then dropped gently to about $2.1 \mathrm{~mm}$ wear before rising slowly again. Similarly, there was a gentle rise of the minimum temperature from 0 to $1.5 \mathrm{~mm}$ wear then dropped gently to about $2.25 \mathrm{~mm}$ wear before rising slowly again. However, the trend for the maximum temperature showed a gradual rise throughout except between $1.25 \mathrm{~mm}$ and $2.0 \mathrm{~mm}$ wear where it almost plateaus. The average temperature of the starting, minimum and the maximum was lower than only the maximum.

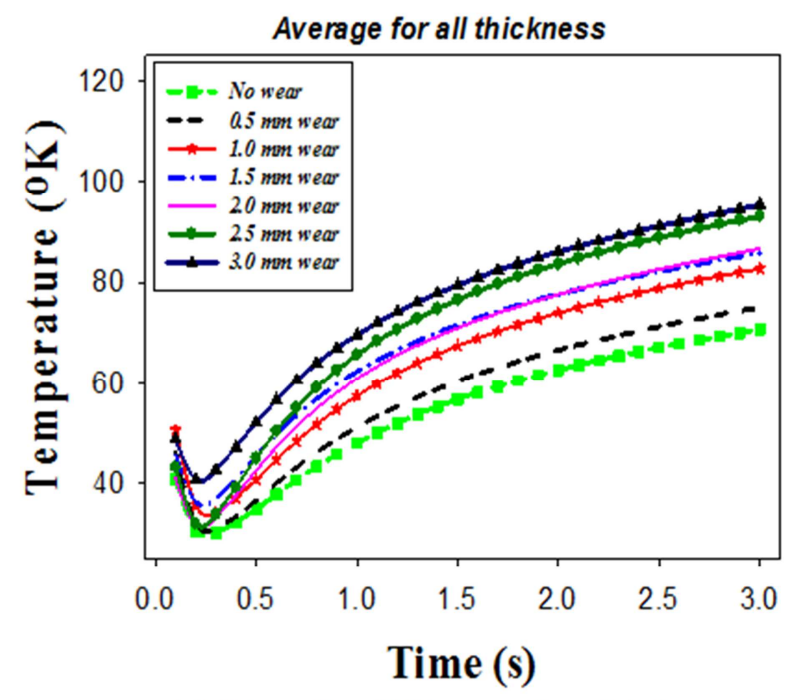

(a) Heat for different disc thickness

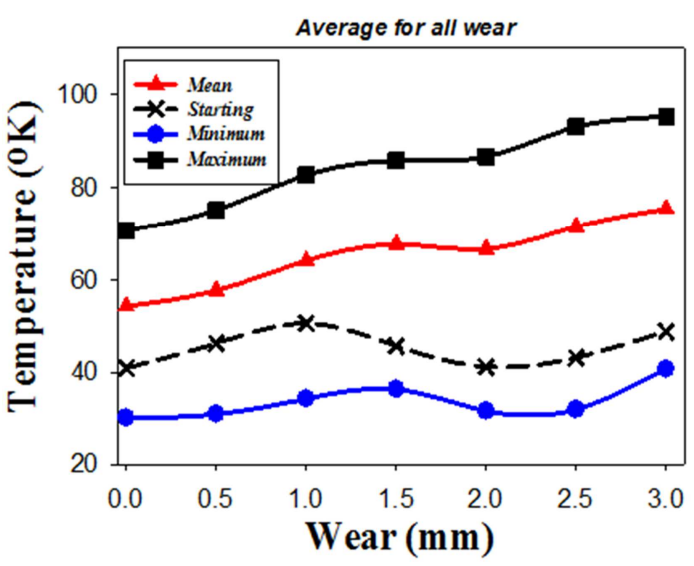

(b) Critical heat

Figure 8. Heat for (a) different wear levels and (b) Critical heat averaged for all wear.

\subsubsection{Effect of Disc Thickness on Percentage Heat Reduction}

The effect of disc thickness on percentage reduction of the friction heat is shown in Figure 9. The trend showed that the friction heat reduces with the increase in the disc thickness. It reduces from $23.4 \%$ at $5.0 \mathrm{~mm}$ to $19 \%$ at $6.0 \mathrm{~mm}$ and reduced sharply after $6.7 \mathrm{~mm}$ to $0 \%$ at $8 \mathrm{~mm}$.

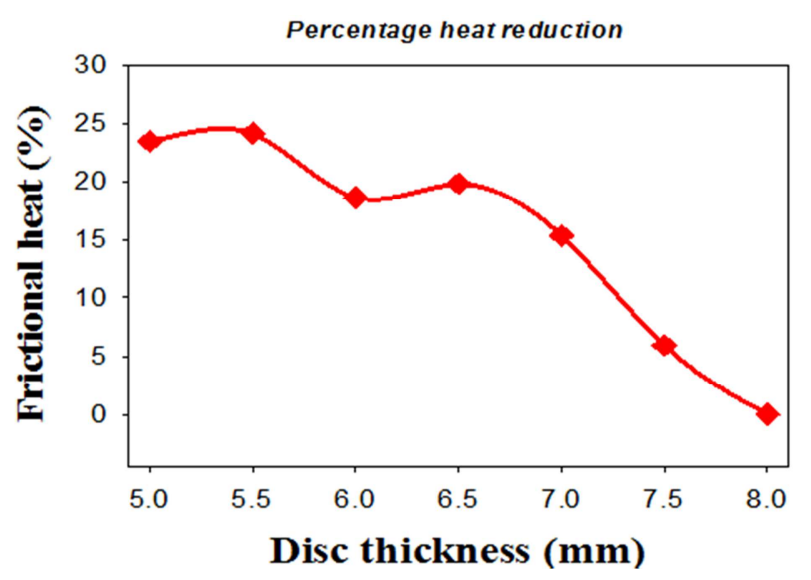

Figure 9. Effect of disc thickness on percentage frictional heat change.

Furthermore, the percentage reduction in the frictional heat showed almost saturation point between $5.8 \mathrm{~mm}$ and $6.7 \mathrm{~mm}$ disc thicknesses. Subsequently, there was an obvious reduction from $6.7 \mathrm{~mm}$ thickness and above. Therefore, the minimum thickness for effective frictional heat and wear reduction which could lead to higher life span of the brake disc is $6.7 \mathrm{~mm}$. This is because the lower the frictional heat, the less the wear and the better the performance of the brake disc [28].

\subsubsection{Critical Temperature Distribution at Different Radii}

The critical temperatures such as the minimum and the time at which they occur for a given radius are presented in Table 5. The results showed that the minimum temperature increases with the increase in disc radius from $6.5 \mathrm{~mm}$ to $8.0 \mathrm{~mm}$. However, the time at which these critical temperatures occur is maintained at $0.3 \mathrm{~s}$ from the $75 \mathrm{~mm}$ and $100 \mathrm{~mm}$ radii but reduces to $0.2 \mathrm{~s}$ with the 
increase in the disc radius at which the temperature was taken. Furthermore, there was a slight drop in the minimum temperature from $5.0 \mathrm{~mm}$ to $6.0 \mathrm{~mm}$ with the increase in the radii from $75 \mathrm{~mm}$ to $100 \mathrm{~mm}$ and then the value of the temperature rose sharply with increase in the radius to $127 \mathrm{~mm}$. Further quantitative analysis indicated that the change in the friction heat moving from $75 \mathrm{~mm}$ to
$100 \mathrm{~mm}$ and $100 \mathrm{~mm}$ to $127 \mathrm{~mm}$ for the $8.0,7.5,7.0$ and $6.5 \mathrm{~mm}$ were $6.1 \%$ and $41.0 \%$ rise; $7.2 \%$ and $28.6 \%$ rise; $5.3 \%$ and $25.1 \%$ rise; $4.2 \%$ and $11.3 \%$ rise respectively. However, the change in the friction heat moving from $75 \mathrm{~mm}$ to $100 \mathrm{~mm}$ and $100 \mathrm{~mm}$ to 127 $\mathrm{mm}$ for the 6.0, 5.5 and $5.0 \mathrm{~mm}$ were $3.3 \%$ drop and $35.3 \%$ rise; $2.5 \%$ drop and $33.7 \%$ rise; $6.2 \%$ and $11.7 \%$ rise respectively.

Table 5. Critical temperatures and the time it developed under different wear.

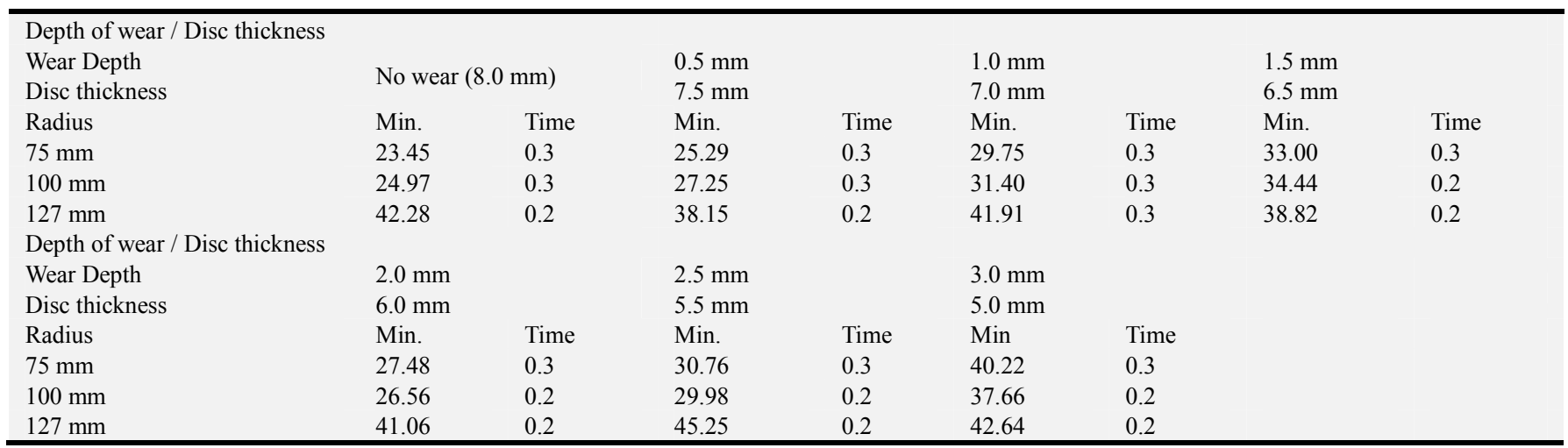

\subsection{Statistical Analysis of the Friction Heat}

\subsubsection{Statistical Evaluation for Different Radii}

Table 6 shows the statistical comparison of the friction heat between the different radii for the disc thicknesses. It can be seen that there was significant difference between the friction heat of the different radii at all the levels of the disc thickness.

Table 6. Differences between response variables for different thicknesses.

\begin{tabular}{lll}
\hline & Between Radii \\
\hline Thickness (mm) & P-values & F-values \\
\hline 5.0 & 0.00369 & 5.9790 \\
5.5 & 0.00075 & 7.8275 \\
6.0 & 0.00011 & 10.1663 \\
6.5 & 0.00032 & 8.8567 \\
7.0 & 0.00148 & 7.0327 \\
7.5 & 0.00050 & 8.3039 \\
8.0 & 0.00228 & 6.5308 \\
\hline
\end{tabular}

\subsubsection{Statistical Evaluation for Different Radii}

Table 7 shows the statistical comparison of the friction heat between the radii and between the disc thicknesses. It can be seen that there was significant difference between the friction heat of the different radii at all the levels of the disc thickness and different disc thicknesses at all levels of the radius. It can be seen that the difference between the disc thickness is much higher than the between the disc radii.

Table 7. Significant differences between response variables.

\begin{tabular}{ll}
\hline Response variables & P-values \\
\hline Between thickness & $2.36 \times 10^{-6}$ \\
Between radii & $1.30 \times 10^{-3}$ \\
\hline
\end{tabular}

\section{Conclusion and Recommendation}

\subsection{Conclusion}

In this paper, the transient thermoelastic analysis of disc brakes in single stop brake applications has been performed using finite element analysis with SolidWorks software. The finite element method was applied to the thermoelastic contact problem with frictional heat generation. Furthermore, the fully implicit scheme is used to improve the accuracy of computations in the transient analysis. Increasing the braking force from $2210 \mathrm{~N}$ to $2875 \mathrm{~N}, 2875$ $\mathrm{N}$ to $3538 \mathrm{~N}$ and $2210 \mathrm{~N}$ to $3538 \mathrm{~N}$ resulted in $28.45 \%$, $33.62 \%$ and $52.5 \%$ deformations respectively. Overall, it can be concluded that the effect of braking force, rotational speed of the disc and the disc thickness under the same condition of treatment can be ranked as; effect of braking force $>$ effect of disc rotational speed $>$ effect of disc thickness. There was a sharp decline in temperature at all the radii points where readings were taken and this could be due initial heat transfer from the disc just at contact. The initial temperature of the pad before contact is always lower than that of the disc because it is separated from the disc, does not rotate and highly ventilated. Therefore, a small portion of the initial heat generated due to contact friction is absorbed by the brake pad material and the amount of heat that is absorbed depends to a large extend on the thermal conductivity of the pad material. The minimum thickness for effective frictional heat and wear reduction which could lead to higher life span of the brake disc is $6.7 \mathrm{~mm}$. The present study can provide a useful design tool and improve the brake performance of disc brake system.

\subsection{Recommendation}

Simulation on successive braking should be carried out to determine the heat dissipation rate for both disc brake systems.

Other simulations must be performed on different disc materials and pads for the purposes of validation of this result.

The effects of friction relating the material properties of contact surfaces needs to be investigated. 


\section{References}

[1] Lamjahdy, A., J. Ali, and B. J. P. Markert, Simulation of the temperature and wear behaviour of a disc brake. 2016. 16 (1): p. 217-218.

[2] Zhang, W., et al., Energy management strategies for hybrid construction machinery: Evolution, classification, comparison and future trends. 2019. 12 (10): p. 2024.

[3] Riva, G., et al., An FEA approach to simulate disc brake wear and airborne particle emissions. 2019. 138: p. 90-98.

[4] Sinha, A., et al., Experimental Characterization Protocols for Wear Products from Disc Brake Materials. 2020. 11 (10): p. 1102.

[5] Grigoratos, T., G. J. E. S. Martini, and P. Research, Brake wear particle emissions: a review. 2015. 22 (4): p. 2491-2504.

[6] Kole, P. J., et al., Wear and tear of tyres: a stealthy source of microplastics in the environment. 2017. 14 (10): p. 1265.

[7] Eriksson, M., F. Bergman, and S. J. W. Jacobson, On the nature of tribological contact in automotive brakes. 2002. 252 (1-2): p. 26-36.

[8] Borawski, A. J. a. m. e. a., Simulation study of the process of friction in the working elements of a car braking system at different degrees of wear. 2018. 12 (3).

[9] Xiao, J.-K., et al., Wear mechanism of Cu-based brake pad for high-speed train braking at speed of $380 \mathrm{~km} / \mathrm{h}$. 2020. 150: p. 106357.

[10] Bakar, A., et al., Thermal Analysis of a Disc Brake Model Considering a Real Brake Pad Surface and Wear. 2010. 2 (1).

[11] Lee, K. and R. B. J. S. t. Dinwiddie, Conditions of frictional contact in disk brakes and their effects on brake judder. 1998: $\mathrm{p}$. 1077-1086.

[12] Friedrich, K. and P. J. M. o. C. M. Reinicke, Friction and wear of polymer-based composites. 1998.34 (6): p. 503-514.

[13] Belhocine, A. J. T. I. J. o. A. M. T., FE prediction of thermal performance and stresses in an automotive disc brake system. 2017. 89 (9-12): p. 3563-3578.

[14] Belhocine, A., et al., Thermal analysis of both ventilated and full disc brake rotors with frictional heat generation. 2014.

[15] Han, M.-J., et al., Low and high cycle fatigue of automotive brake discs using coupled thermo-mechanical finite element analysis under thermal loading. 2018. 32 (12): p. 5777-5784.

[16] Adamowicz, A. and P. J. a. m. e. a. Grześ, Finite element analysis of thermal stresses in a pad-disc brake system (a review). 2013.7 (4).

[17] Yevtushenko, A. and P. J. N. H. T. Grzes, Part A: Applications, The FEM-modeling of the frictional heating phenomenon in the pad/disc tribosystem (a review). 2010. 58 (3): p. 207-226.

[18] Yevtushenko, A., P. J. I. C. i. H. Grzes, and M. Transfer, $3 D$ FE model of frictional heating and wear with a mutual influence of the sliding velocity and temperature in a disc brake. 2015. 62: p. 37-44.

[19] Shäfer, J., S. Dippel, and D. J. J. d. p. I. Wolf, Force schemes in simulations of granular materials. 1996. 6 (1): p. 5-20.

[20] Lee, Y., et al., A predictive tool to evaluate disc brake squeal propensity. Part 1: the model philosophy and the contact problem. 2003. 31 (3): p. 289-308.

[21] Shanker, P. S. J. M. T. P., A review on properties of conventional and metal matrix composite materials in manufacturing of disc brake. 2018.5 (2): p. 5864-5869.

[22] Hwang, A., Wu, X. Investigation of Temperature and Thermal Stress in Ventilated Disc Brake based on 3D Thermo-Mechanical Coupling Model, Journal of Mechanical Science and Technology, 2010. 24, p. 81-84.

[23] Pyryev Y. and Yevtushenko A. The influence of brake friction element thickness on the content temperature and wear, Heat and Mass Transfer, 2000. p. 319 - 323.

[24] Wang, Z., et al., Temperature evolution of the train brake disc during high-speed braking, Advances in Mechanical Engineering, 2019, 11 (1): p. 1-10.

[25] Yevtushenko A. A. and Grzes P. 3D FE model of frictional heating and wear with a mutual influence of the sliding velocity and temperature in a disc brake. Int Commun. Heat Mass, 2015; 62: p. 37-44.

[26] Talati, F. and Jalalifar S. Analysis of heat conduction in a disk brake system, Heat Mass Transfer. 2009. 45: p. 1047-1059.

[27] Gao, C. H. and Lin, X. Z. Transient temperature field analysis of a brake in a non-axisymmetric three-dimensional model", Journal of Materials Processing Technology, 2002. 129: p. 513-517.

[28] Belhocine, A. and Bouchetara, M. Thermal analysis of a solid brake disc, Applied Thermal Engineering, 2012. 32: p. 59-67. 